08;15

\title{
Применение электростатической силовой микроскопии для оценки проводимости индивидуальных многостенных углеродных нанотрубок
}

\author{
(C) Н.А. Давлеткильдеев ${ }^{1,2}$, Д.В. Соколов ${ }^{1}$, В.В. Болотов ${ }^{1}$, \\ И.А. Лобов ${ }^{1,2}$ \\ ${ }^{1}$ Омский научный центр Сибирского отделения РАН \\ ${ }^{2}$ Омский государственный университет им. Ф.М. Достоевского \\ E-mail: nadim@obisp.oscsbras.ru
}

Поступило в Редакцию 26 сентября 2016 г.

Методом электростатической силовой микроскопии (ЭСМ) исследована электрическая проводимость индивидуальных многостенных углеродных нанотрубок (УНТ), легированных азотом: синтезированных, термически обработанных в инертной атмосфере и облученных ионами аргона. На основе моделирования профиля поперечного сечения ЭСМ-изображения УНТ определялся

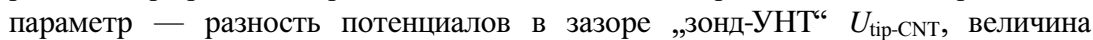
которого задается проводимостью нанотрубки. Установлена сильная корреляционная зависимость между объемной удельной проводимостью слоя УНТ и усредненным параметром $U_{\text {tip-CNT }}$ для всех типов исследованных нанотрубок. Показано, что изменение проводимости легированных УНТ, подвергнутых термическому отжигу или облучению ионами аргона, является следствием изменения состава и концентрации дефектов в стенках УНТ.

DOI: 10.21883/PJTF.2017.04.44297.16489

Углеродные нанотрубки (УНТ), благодаря своим уникальным свойствам и морфологии, активно исследуются как перспективный материал для различных приложений, таких как полевые эмиттеры, топливные ячейки, сенсоры [1,2]. Эффективным способом модификации электрических свойств УНТ является легирование их другими элементами. Наиболее эффективным элементом для легирования УНТ является азот [3]. Преимуществом легированных азотом УНТ является то, что их электрические свойства в основном определяются составом дефектов, 
который можно контролировать в процессе синтеза и последующих обработок.

Перспектива создания элементов электроники на одиночных УНТ определяет необходимость развития методов контроля электрических характеристик индивидуальных УНТ. Большинство методов характеризации электрических свойств индивидуальных УНТ требует создания электрических контактов к нанотрубке. Зачастую это технологически сложно и позволяет получать результаты для ограниченного числа УНТ. Эффективным бесконтактным методом исследования электрических свойств индивидуальных УНТ является электростатическая силовая микроскопия (ЭСМ) [4,5].

В данной работе представлена методика оценки электрической проводимости индивидуальных многостенных УНТ по величине напряжения в зазоре „зонд-УНТ“, определяемого из анализа профиля поперечного сечения ЭСМ-изображений с использованием модели, описанной в работе [6]. Представленная методика опробована на легированных азотом УНТ с различной величиной проводимости, обеспечиваемой термической и радиационной обработкой исходных синтезированных УНТ.

Многостенные УНТ синтезировались методом химического парофазного осаждения в результате пиролиза паров толуола (для нелегированных УНТ) и ацетонитрила (для легированных азотом УНТ) при $850^{\circ} \mathrm{C}$ с добавлением ферроцена в качестве источника катализатора $\mathrm{Fe}$. Для варьирования проводимости легированных УНТ проводились их термическая обработка в атмосфере аргона при температуре $800^{\circ} \mathrm{C}$ в течение $30 \mathrm{~min}$ и облучение ионами аргона с энергией $15 \mathrm{keV}$ и дозой $10^{15} \mathrm{~cm}^{-2}$. Элементный и дефектный состав УНТ, осажденных в виде сплошного слоя на проводящую подложку, исследовался методом рентгеновской фотоэлектронной спектроскопии (РФЭС) на аналитическом комплексе Surface Science Center (Riber). Удельное сопротивление слоев УНТ, осажденных в виде сплошного слоя на диэлектрическую подложку, определялось стандартным четырехзондовым методом на зондовой станции 13 МП-0.5-001. ЭСМ-измерения выполнялись на атомно-силовом микроскопе MFP-3D SA (Asylum Research) в Омском региональном ЦКП СО РАН. Методика ЭСМ-измерений подробно описана в работе [6].

Контраст полученных ЭСМ-изображений (рис. 1,a) демонстрирует проводящий характер всех исследованных УНТ. Форма профиля поперечного сечения ЭСМ-изображения нанотрубки имеет „М-образный“

Письма в ЖТФ, 2017, том 43, вып. 4 


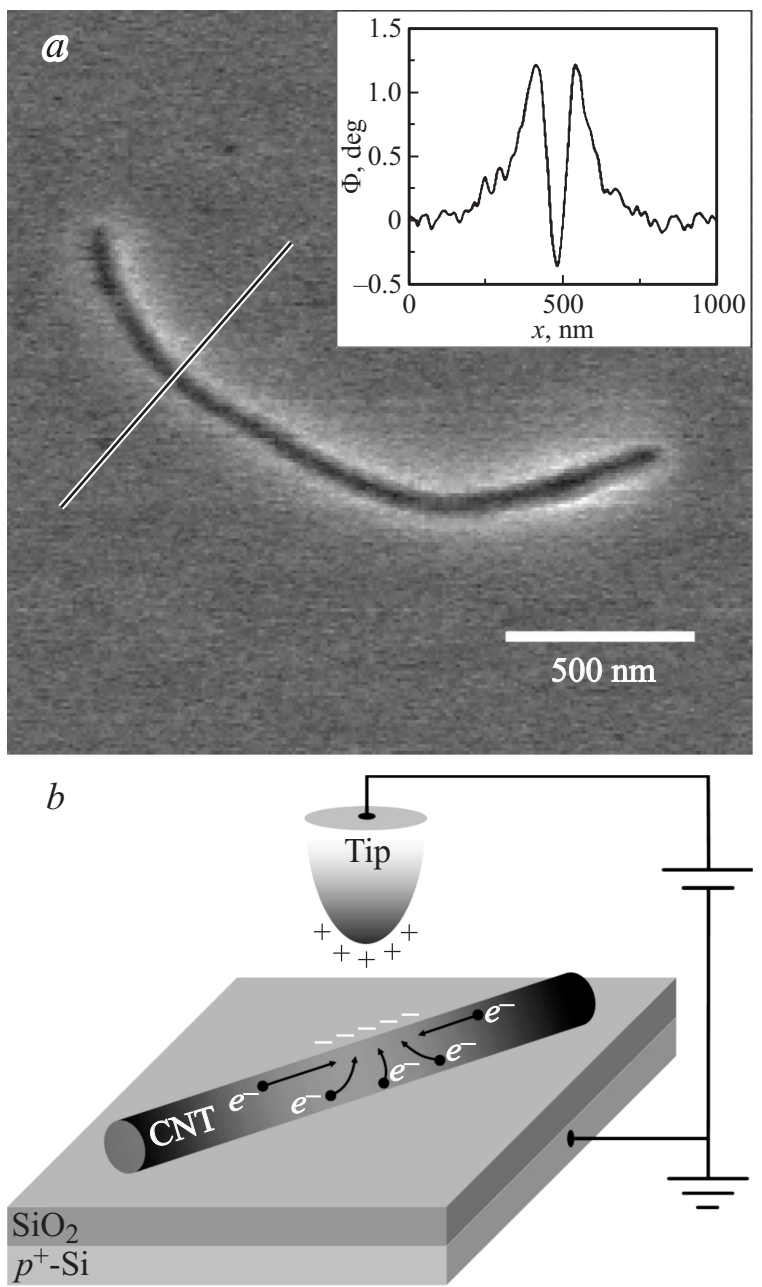

Рис. 1. Типичное ЭСМ-изображение УНТ $(a)$, на вставке - профиль поперечного сечения ЭСМ-изображения УНТ; $b-$ схематическая иллюстрация, поясняющая связь разности потенциалов в зазоре „зонд-УНТ“ $U_{\text {tip-CNT }}$ с проводимостью УНТ.

4 Письма в ЖТФ, 2017, том 43, вып. 4 
вид (рис. $1, a$, вставка): возрастание сигнала вокруг УНТ обусловлено электростатическим взаимодействием зонда с нанотрубкой благодаря наличию в ней свободных носителей заряда; уменьшение ЭСМ-сигнала в центре профиля связано с ослаблением емкостной связи „зондподложка“ при нахождении зонда над нанотрубкой за счет частичного экранирования емкостной связи проводящей УНТ и увеличения расстояния между подложкой и зондом при его подъеме над нанотрубкой.

Анализ профиля ЭСМ-сигнала проводился на основе модели, рассматривающей емкостные связи „зонд-подложка“, „зонд-УНТ“, „УНТ-подложка“, которая подробно описана в работе [6]. При расчете модельных профилей ЭСМ-сигнала учитывались реальные параметры УНТ, зонда, кантилевера и подложки. Различие в проводимости УНТ учитывалось с помощью дополнительного вычитаемого $\Delta U$ из разности потенциалов в конденсаторе „зонд-УНТ“ $U_{\text {tip-СNT }}$ (уравнение (4) в [6]). $\Delta U$ представляет собой поправку к напряжению $U_{\text {tip-CNT, }}$ которая учитывает различие в концентрации электронов в металлическом зонде (порядка $10^{22} \mathrm{~cm}^{-3}$ ) и УНТ (порядка $10^{18} \mathrm{~cm}^{-3}$ ). Таким образом, с учетом поправки $\Delta U$ величина $U_{\text {tip-CNT }}$ лимитируется плотностью заряда, локализованного на поверхности УНТ непосредственно под зондом, который, в свою очередь, определяется концентрацией и подвижностью носителей заряда, т.е. проводимостью УНТ (рис. $1, b$ ).

На рис. 2, $a$ в качестве примера представлены профили ЭСМ-сигнала нелегированной и легированной азотом УНТ с идентичным внешним диаметром $17 \mathrm{~nm}$. Легированная УНТ дает более низкий уровень ЭСМ-сигнала. Качественное и количественное согласие между экспериментальными и модельными профилями достигается уменьшением разности потенциалов между зондом и нанотрубкой $U_{\text {tip-CNT для легиро- }}$ ванной УНТ на $0.5 \mathrm{~V}$. Уменьшение величины $U_{\text {tip-сNT }}$ свидетельствует о более низкой проводимости легированной УНТ по сравнению с нелегированной.

На рис. $2, b$ в качестве примера представлены профили ЭСМ-сигнала синтезированной и термически обработанной легированных УНТ с внешним диаметром $13 \mathrm{~nm}$. Термообработанные УНТ характеризуются большей величиной ЭСМ-сигнала и меньшей глубиной падения сигнала в центре профиля. Экспериментальные и модельные профили ЭСМ-сигнала согласуются между собой при увеличении параметра

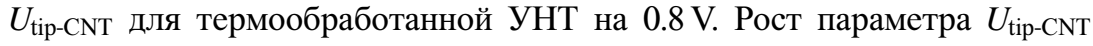
свидетельствует об увеличении проводимости УНТ после термического отжига. 

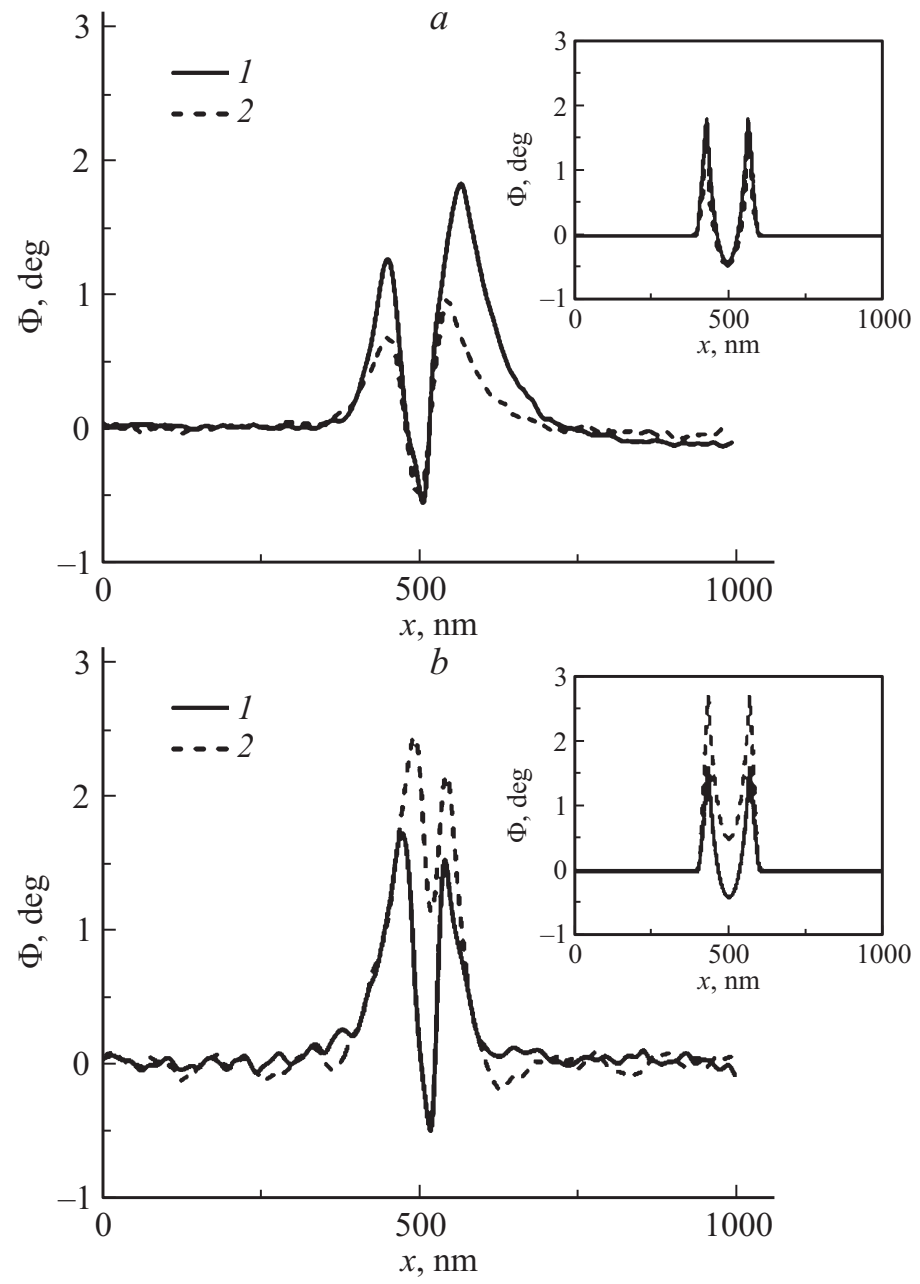

Рис. 2. Экспериментальные и модельные (на вставках) профили ЭСМ-сигнала: $a-$ нелегированной 1 и легированной азотом 2 УНТ диаметром $17 \mathrm{~nm}$; $b$ - синтезированной 1 и термически обработанной 2 легированных УНТ диаметром $13 \mathrm{~nm}$; $c$ - синтезированной 1 и облученной 2 легированных УНТ диаметром $15 \mathrm{~nm}$.

$4^{*}$ Письма в ЖТФ, 2017, том 43, вып. 4 


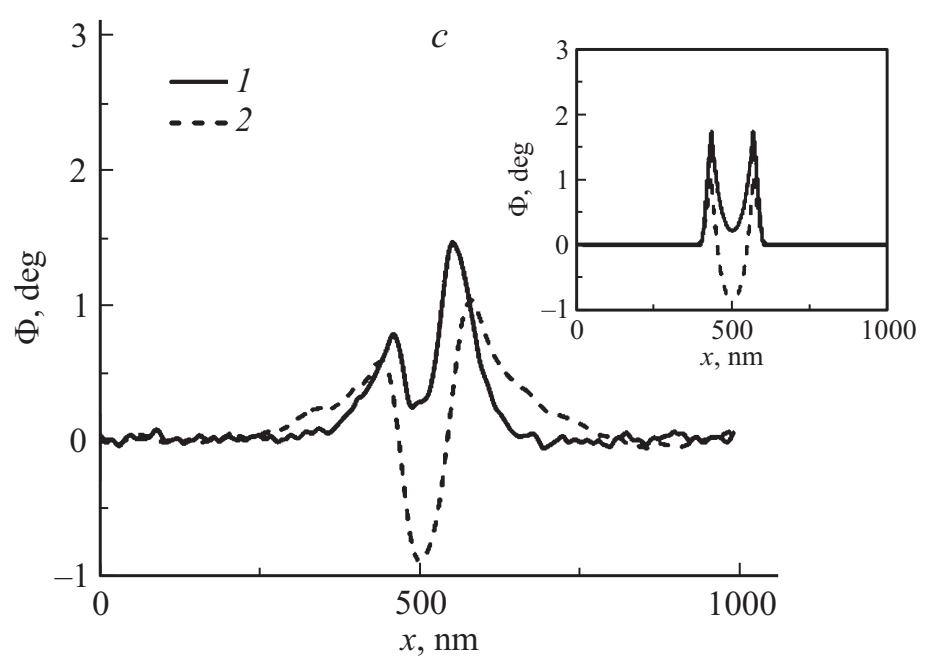

Рис. 2 (продолжение).

На рис. 2, $c$ показаны профили ЭСМ-сигнала исходной и облученной легированных УНТ с внешним диаметром $15 \mathrm{~nm}$. Облученные УНТ характеризуются меньшей величиной ЭСМ-сигнала и значительным падением сигнала в центре профиля. Согласие между экспериментальными и модельными профилями ЭСМ-сигнала реализуется при

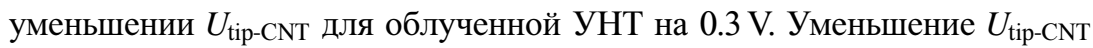
свидетельствует о снижении проводимости УНТ после облучения ионами аргона.

Для определения связи параметра $U_{\text {tip-CNT }}$ с реальной проводимостью УНТ были проведены измерения удельной проводимости слоев УНТ с помощью четырехзондового метода. Для графического представления такой связи построим корреляционную зависимость среднего значения параметра $U_{\text {tip-CNT }}$ и удельной проводимости слоев для всех типов исследованных УНТ (рис. 3). Полученная зависимость демонстрирует сильную положительную корреляционную связь между величиной

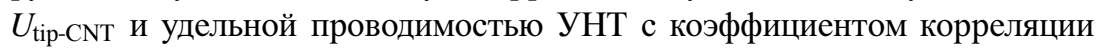
Пирсона, близким к единице. Данная статистическая связь показывает,

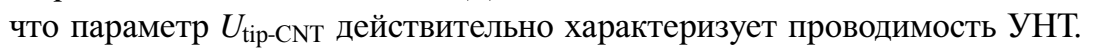

Письма в ЖТФ, 2017, том 43, вып. 4 


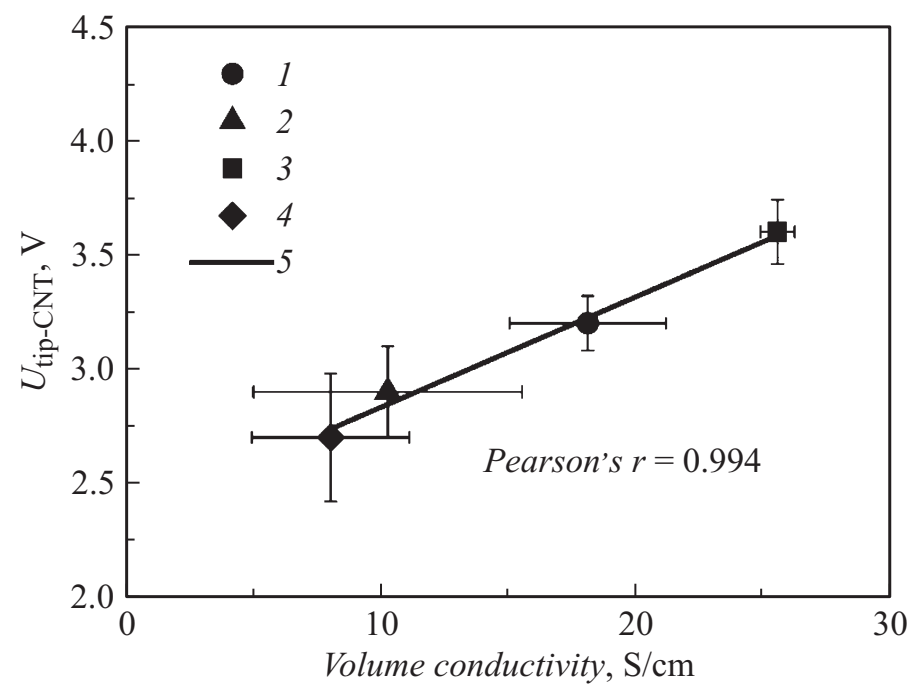

Рис. 3. Корреляционная зависимость между объемной удельной проводимостью

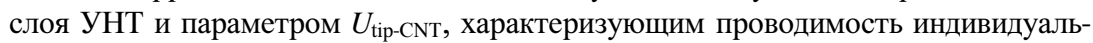
ной УНТ: 1 - нелегированные УНТ, 2 - синтезированные легированные УНТ, 3 - термически обработанные легированные УНТ, 4 - облученные легированные УНТ, 5 - линейная аппроксимация данных.

Величина проводимости слоя УНТ зависит от проводимости индивидуальных нанотрубок, но контролируется количеством контактов между ними [7]. Чем больше контактов между УНТ, тем меньше проводимость слоя. Наибольшее количество контактов будет наблюдаться в слое, состоящем из коротких УНТ. Поэтому основным параметром, отвечающим за проводимость слоя, является длина нанотрубки. Согласно результатам анализа ЭСМ-изображений, средняя длина для легированных УНТ, как исходных, так и обработанных, одинакова и составляет около $2.1 \pm 0.8 \mu \mathrm{m}$, в то время как для нелегированных $-1.1 \pm 0.6 \mu \mathrm{m}$. Идентичность длины легированных УНТ позволяет говорить о том, что изменение удельной проводимости слоев легированных УНТ после термической и радиационной обработок определяется изменением проводимости индивидуальных УНТ.

Письма в ЖТФ, 2017, том 43, вып. 4 
Результаты количественного РФЭС анализа дефектного состава синтезированных, термообработанных и облученных легированных азотом УНТ

\begin{tabular}{l|c|c|c|c}
\hline \multirow{2}{*}{ Образец } & \multirow{2}{*}{$\begin{array}{c}\text { Содержание } \\
\text { азота, at.\% }\end{array}$} & \multicolumn{3}{|c}{ Доля азотсодержащих дефектов } \\
\cline { 3 - 5 } & & $\mathrm{N}_{\mathrm{OX}}$ & $\mathrm{N}_{\mathrm{Q}}$ & $\mathrm{N}_{\mathrm{PYR}}$ \\
\hline Синтезированные УНТ & 3.7 & 34 & 46 & 20 \\
Термообработанные УНТ & 2.8 & - & 44 & 56 \\
Облученные УНТ & 1.5 & 28 & 72 & -
\end{tabular}

Изменение проводимости легированных УНТ, подвергнутых термическому отжигу или облучению ионами аргона, является следствием изменения состава и концентрации дефектов в стенках УНТ. Согласно данным РФЭС (см. таблицу), в синтезированных УНТ доминируют три типа азотсодержащих дефектов: графитоподобный $\left(\mathrm{N}_{\mathrm{Q}}\right)$, пиридиноподобный $\left(\mathrm{N}_{\mathrm{PYR}}\right)$ и оксидированный $\left(\mathrm{N}_{\mathrm{OX}}\right)$ азот. При термической обработке легированных УНТ термически нестабильный оксидированный азот распадается и переходит в электрически активную пиридиноподобную форму, обеспечивая рост проводимости УНТ [8]. Подобная трансформация азотсодержащих дефектов, наряду с отжигом собственных дефектов графенового слоя и восстановлением сети делокализованных $\pi$-электронов, приводит к увеличению проводимости УНТ. Облучение легированных УНТ ионами аргона уменьшает концентрацию электрически активных форм азотсодержащих дефектов на фоне значительного падения общей концентрации азота (см. таблицу). Кроме того, облучение ионами аргона создает радиационные дефекты в стенке УНТ, в результате чего разрушается сеть $\pi$-электронов, снижается концентрация свободных электронов и растет концентрация центров рассеяния.

Таким образом, на основе моделирования профиля поперечного сечения ЭСМ-изображения УНТ предложена методика оценки проводимости индивидуальных УНТ. Показано, что параметр, характеризующий проводимость индивидуальных УНТ, строго коррелирует с объемной удельной проводимостью слоев УНТ. Показано, что рост проводимости легированных азотом УНТ после термического отжига обеспечивается увеличением доли электрически активных азотсодержащих дефектов. Облучение легированных УНТ ионами аргона вызывает уменьшение их проводимости. 
Авторы выражают благодарность Стенькину Ю.А. за синтез УНТ, Поворознюку С.Н. за облучение УНТ, Корусенко П.М. и Несову С.Н. за измерения РФЭ-спектров. Работа выполнена при частичной поддержке грантов РФФИ № 15-48-04134p_сибирь_а и 16-08-00763а.

\section{Список литературы}

[1] Елецкий А.В. // Успехи физических наук. 2010. Т. 180. В. 9. С. 897-930.

[2] Yang N., Chen X., Ren T. et al. // Sensor Actuat. B. Chem. 2015. V. 207. P. 690 715.

[3] Ayala P., Arenal R., Rümmeli M. et al. // Carbon. 2010. V. 48. P. 575-586.

[4] Mélin T., Zdrojek M., Brunel D. // Scanning Probe Microscopy in Nanoscience and Nanotechnology / Ed. B. Bhushan. Berlin, Heidelberg: Springer-Verlag, 2010. Ch. 4. P. $89-128$

[5] Barboza A.P.M., Gomes A.P., Chacham H., Neves B.R.A. // Carbon. 2010. V. 48. P. 3287-3292.

[6] Болотов В.В., Давлеткильдеев Н.А., Стецько Д.В., Лобов И.А. // Письма в ЖТФ. 2014. Т. 40. В. 21. С. 63-70.

[7] Wiggins-Camacho J.D., Stevenson K.J. // J. Phys. Chem. C. 2009. V. 113. P. 19082-19090.

[8] Fujisawa K., Tojo T., Muramatsu H. et al. // Nanoscale. 2011. V. 3. P. 4359-4364.

Письма в ЖТФ, 2017, том 43, вып. 4 